\title{
IS THE INCREASE IN DIESEL VEHICLES A HEALTH HAZARD FOR SRI LANKA?
}

\author{
SD Dharmaratne \\ Department of Co:nmunity Medicine, Faculty of Medicine, \\ University of Peradeniya, Perdeniya
}

It is proven that this diesel fumes, in the presence of sunlight, Oxygen and Nitrogen produces a substance, which is carcinogenic to the human being. Therefore This study was conducted with the objectives of determining whether the number of diesel vehicles imported to Sri Lanka during the last three decades has increased proportionately over the petrol vehicle; determining whether the diesel consumption has increased over petrol consumption in Sri Lanka during the same period; determining whether the number of patients with Lung Cancer had increased in Sri Lanka concurrently.

The Motor Traffic Department Data from 1970 to 1996 and the Petroleum Corporation data from 1982 to 1996 were analysed usirg SPSS10.1 statistical software. The data from the Cancer Control Program was available only for three years. The Motor Traffic Department has categorized the Class of vehicle into Cars and Three Wheelers, Motor Cycles, Buses, Dual Purpose vehicles, Lorries and Land Vehicles. It was assumed that of these types, the bus, the lorry and the dual-purpose vehicle are diesel driven.

In 1970 there were 48,034 buses and lorries in Sri Lanka. This was $27.2 \%$ of the total vehicle population. This nearby doubled to 81,910 in 1980 , which constituted $24.3 \%$ of the total vehicle population. Till 1985, no dual-purpose vehicle was registered in the country. In 1985, this total increased to $138,289(26.4 \%)$, which included 1121 dual-purpose vehicles. The dual-purpose vehicle was only $0.2 \%$ of the total vehicle population in this year.

The total number of buses, lorries ard dual-purpose vehicles increased to 165,626 in 1990 and to 283,174 in 1995 . These were $20.2 \%$ and $22.2 \%$ of the total vehicle population in these two years. The number of dual-purpose vehicles in these two years was, 19,622 and 68,857 respectively. These as a proportion of the total vehicle population were 2.4 and 5.4 per cent respectively. In 1996 , the dual-purpose vehicle increased to $83,114,6.3$ per cent of the total vehicle population.

The petrol consumption, which was 121.6 thousand tonnes in 1985, increased to 181.1 in 1990 and to 189.7 in 1995 . The comparable figures for diesel consumption were $488.5,511.1$ and 816.4. The diagnosed cases of patients with Lung Cancer in Sri Lanka were 358 in 1985, which increased to 581 in 1990 and to 665 in 1995 . It can be concluded that the dual-purpose vehicle has increased during the last part of the twentieth century.

Consumption of diesel has increase 1 tremendously while the petrol consumption had virtually been constant and that lung cancer also had increased. Based on the findings it is recommended to reduce the number of diesel vehicles used for domestic use. But for this the cost of fuel prices will have to be adjusted or, strict lau s prohibiting the use of diesel vehicles for domestic use will have to be imposed and implemented. Whether the increase in the diesel consumption has caused this increase in the number of lung cancer patients is not clear. 